Research Paper

\title{
The prevalence, associated factors for bone metastases development and prognosis in newly diagnosed ovarian cancer: a large population based real-world study
}

\author{
Chao Zhang1, Xu Guo1,6, Karl Peltzer³, Wenjuan Ma4, Lisha Qi5, Yanting Zhang1, Xiuxin Han', Vladimir P.
} Baklaushev ${ }^{9}$, Yueliang Yao ${ }^{8}$, Guowen Wang${ }^{1}$, Vladimir P. Chekhonin 7 , Xin Wang ${ }^{2 \bowtie}$, Yulin Ma ${ }^{\bowtie}$

1. Department of Bone and Soft Tissue Tumors, Tianjin Medical University Cancer Institute and Hospital, National Clinical Research Center for Cancer, Key Laboratory of Cancer Prevention and Therapy, Tianjin's Clinical Research Center for Cancer, Tianjin, China.

2. Department of Epidemiology and Biostatistics, First Affiliated Hospital, Army Medical University, Chongqing, China.

3. Department of Research \& Innovation, University of Limpopo, Turfloop, South Africa.

4. Department of Breast Imaging, Tianjin Medical University Cancer Institute and Hospital, National Clinical Research Center for Cancer, Key Laboratory of Cancer Prevention and Therapy, Tianjin's Clinical Research Center for Cancer, Tianjin, China.

5. Department of Pathology, Tianjin Medical University Cancer Institute and Hospital, National Clinical Research Center for Cancer, Key Laboratory of Cancer Prevention and Therapy, Tianjin's Clinical Research Center for Cancer, Tianjin, China.

6. Department of Orthopedics, Cangzhou Central Hospital, Cangzhou, Hebei, China.

7. Department of Fundamental and Applied Neurobiology, V. P. Serbsky Federal Medical Research Center of Psychiatry and Narcology, the Ministry of Health of the Russian Federation, Moscow, Russian Federation.

8. Institute of Pathology and Southwest Cancer Center, Southwest Hospital, Army Medical University (Third Military Medical University), Chongqing, China.

9. Federal Research and Clinical Center of Specialized Medical Care and Medical Technologies, Federal Biomedical Agency of the Russian Federation, Moscow, Russian Federation.

$\triangle$ Corresponding authors: Dr. Xin Wang, address: First Affiliated Hospital, Army Medical University, 30 Gaotanyan Street Shapingba District, Chongqing 400038, China. E-mail: wangxinmarine@126.com or Dr. Yulin Ma, address: Tianjin Medical University Cancer Institute and Hospital, Huanhu Xi Road, Tiyuan Bei, Hexi District, Tianjin 300060, P. R. China. E-mail: mayulintj@163.com

( $)$ Ivyspring International Publisher. This is an open access article distributed under the terms of the Creative Commons Attribution (CC BY-NC) license (https://creativecommons.org/licenses/by-nc/4.0/). See http://ivyspring.com/terms for full terms and conditions.

Received: 2018.10.01; Accepted: 2019.04.03; Published: 2019.06.02

\begin{abstract}
Background: Ovarian cancer $(O C)$ is one of the most common malignancies in women. Advanced bone metastases (BM) commonly result in the poor prognosis. We aim to evaluate the prevalence and associated factors for the de novo BM development and prognosis in OC.

Materials and methods: The present study was a cohort study that used the United States based National Cancer Institute's Surveillance, Epidemiology, and End Results (SEER) database. SEER documented OC patients, diagnosed between 2010 and 2015, were included in the present study. Univariable and multivariable logistic regression analyses were employed to identify associated factors for BM development. Kaplan-Meier analysis was used to estimate the overall survival and multivariable proportional hazard regression was used to identify the prognostic factors for OC patients with BM.

Results: A total of 32,178 eligible $O C$ patients were included in the present study, the prevalence of de novo $\mathrm{BM}$ was $1.09 \%(\mathrm{~N}=352)$. Non-serous histology [Odds Ratio $(\mathrm{OR})=3.05 ; 95 \% \mathrm{Cl}$ : $1.63-5.72$; $P=0.001$ ], T2/T1 stage $(\mathrm{OR}=3.39 ; 95 \% \mathrm{Cl}: 1.11-10.33 ; P=0.03), \mathrm{N} 1 / \mathrm{N} 0$ stage $(\mathrm{OR}=3.17 ; 95 \% \mathrm{Cl}$ : 1.72-5.84; $P<0.001)$, and the presence of lung $(\mathrm{OR}=8.57 ; 95 \% \mathrm{Cl}: 4.37-16.80 ; P<0.001)$ and liver metastases $(\mathrm{OR}=4.95 ; 95 \% \mathrm{Cl}: 2.50-9.82 ; P<0.001)$ were all significantly associated with de novo $\mathrm{BM}$ development. Median survival for OC with BM was 5.00 (95\% Cl: 3.76-6.24) months. Multivariable Cox regression showed serous histology [Hazard ratio $(\mathrm{HR})=1.44 ; 95 \% \mathrm{Cl}$ : $1.01-2.06 ; \mathrm{P}=0.046$ ] was positively associated with overall death, while surgery of the primary site $(\mathrm{HR}=0.42 ; 95 \% \mathrm{Cl}: 0.29-0.61 ; P<0.001)$ was negatively associated with overall death.
\end{abstract}

Conclusion: Bone metastasis is rare in ovarian cancer patients. The factors associated with BM development and prognosis can be potentially used for BM early screening and individualized treatment.

Key words: bone metastases, ovary cancer, associated factor, prognosis, SEER 


\section{Introduction}

Ovarian cancer (OC) is one of the most common malignancies in women, which accounts for $2.5 \%$ of cancers in women [1-2]. Approximately 13,850 women died from OC annually, being one of the leading reasons for cancer deaths in women in the United States and the 5-year survival rate for women with all types of ovarian cancer was around 47\% [3-5]. More than $60 \%$ OC patients were diagnosed at an advanced stage, with de novo distant metastases, which can partly explain the high mortality rate [6].

In the latest study, bone was reported to be the fourth common metastatic sites followed by liver, distant lymph nodes and lung [7]. Advanced bone metastases (BM) commonly result in skeletal related events (SREs), including pathological fracture, pain, bone marrow aplasia, spinal cord compression, and malignant hypercalcemia, which significantly worsen the quality of life $[8,9]$.

There are no current routine BM screening guidelines for OC patients. Survival rates are lower than other cancers as OC lacks specific early symptoms, which delays diagnosis and treatment [10]. In order to improve $\mathrm{BM}$ identification and provide early screening for $\mathrm{BM}$, the study focused on the risk factors of BM occurrence in OC.

Early estimation of the prognosis for metastatic OC can help the physicians to develop targeted treatment regimens. Prophylactic treatment and attentive nursing care can be given to the patients with high risk to improve the prognosis. However, limited studies on the survival estimates of bone metastatic OC patients were performed before.

National Cancer Institute's Surveillance, Epidemiology, and End Results (SEER), as the largest publicly available cancer dataset, covers approximately $30 \%$ of the US population and routinely records patients' demographics, tumor characteristics, general treatment, survival time, and annually updated vital status. The primary aim of the present study was to investigate the prevalence and the risk factors of de novo BM in OC in the SEER dataset. The secondary aim was to explore the over survival and prognostic factors of OC with de novo BM.

\section{Methods}

\section{Study population}

Adult OC patients were identified using the SEER database. Primary OC patients initially diagnosed between 2010 and 2015 were collected (the details of BM were not recorded before 2010, and the latest data up to date is to December 31, 2015). The site recodes ICD-O-3 (International Classification of Diseases for Oncology-3)/WHO 2008 was restricted as "Ovarian". The exclusion criteria were as follows: patients younger than 18 years old; diagnosed with carcinoma in situ, benign or borderline tumors, diagnosed at autopsy or via death certificate, unknown information for BM or follow-up. SEER*Stat 8.3.5 software (https://seer.cancer.gov/data/) was used to generate the case listing.

\section{Study design}

It was a population-based cohort study. The prevalence and associated factors for BM were described using OC patients diagnosed from January 1, 2010, to December 31, 2015. The OC patients with BM were followed up to conduct survival analysis and investigate the prognostic factors.

\section{Statistical analysis}

Patients' demographic and clinical characteristics were defined as follows: age (18-40, 41-64 and $\geq 65$ years), race (white, black and others), marital status (married and unmarried), insurance status (insured and uninsured), laterality (left, right and bilateral), primary tumor stage ( $\mathrm{T}$ stage: $\mathrm{T} 1, \mathrm{~T} 2$ and $\mathrm{T} 3$ ), regional lymph node stage ( $\mathrm{N}$ stage: $\mathrm{N} 0$ and $\mathrm{N} 1$ ), tumor grade (I=well differentiated, II=moderately differentiated, III=poorly differentiated and IV=undifferentiated and anaplastic), histology (serous and non-serous), cancer antigen 125 (CA-125: normal and elevated), and the presence of lung metastases, liver metastases, and brain metastases. Quantitative data were described as mean \pm standard deviation (SD) and the difference between groups were analysed by student's t-test. Categorical data were presented as number and the percentage $(\mathrm{N}, \%)$ and the differences were tested by Pearson chi-square test. The risk factors for OC patients with initial $\mathrm{BM}$ were determined primarily by univariable logistic regression. The characteristics with $P<0.05$ in the univariable logistic regression analysis were considered as candidates for the multivariable logistic analysis. The overall survival was estimated by Kaplan-Meier method and the difference between distinct groups was compared using the log-rank test. Multivariable Cox regression model, incorporating the significant factors in univariate Cox regression $(P<0.05)$ was conducted for analyzing the independent prognostic factors for BM.

All statistical analyses were performed using SPSS 23.0 (IBM Corporation, Armonk, NY) and all survival curves were conducted by MedCalc 15.2.2. A two-tailed $P$ value $<0.05$ was considered statistically significant in all analyses. 


\section{Results}

\section{Demographic and clinical characteristics}

A total of 32,178 OC patients met the inclusion criteria (Figure 1). The patients' mean age was 61.82 \pm 14.97 years. Among these patients, 352 OC patients with $\mathrm{BM}$ were retrieved, and the mean age of them was $65.61 \pm 15.12$ years. The demographic and clinical characteristics of the included patients were shown in Table 1.

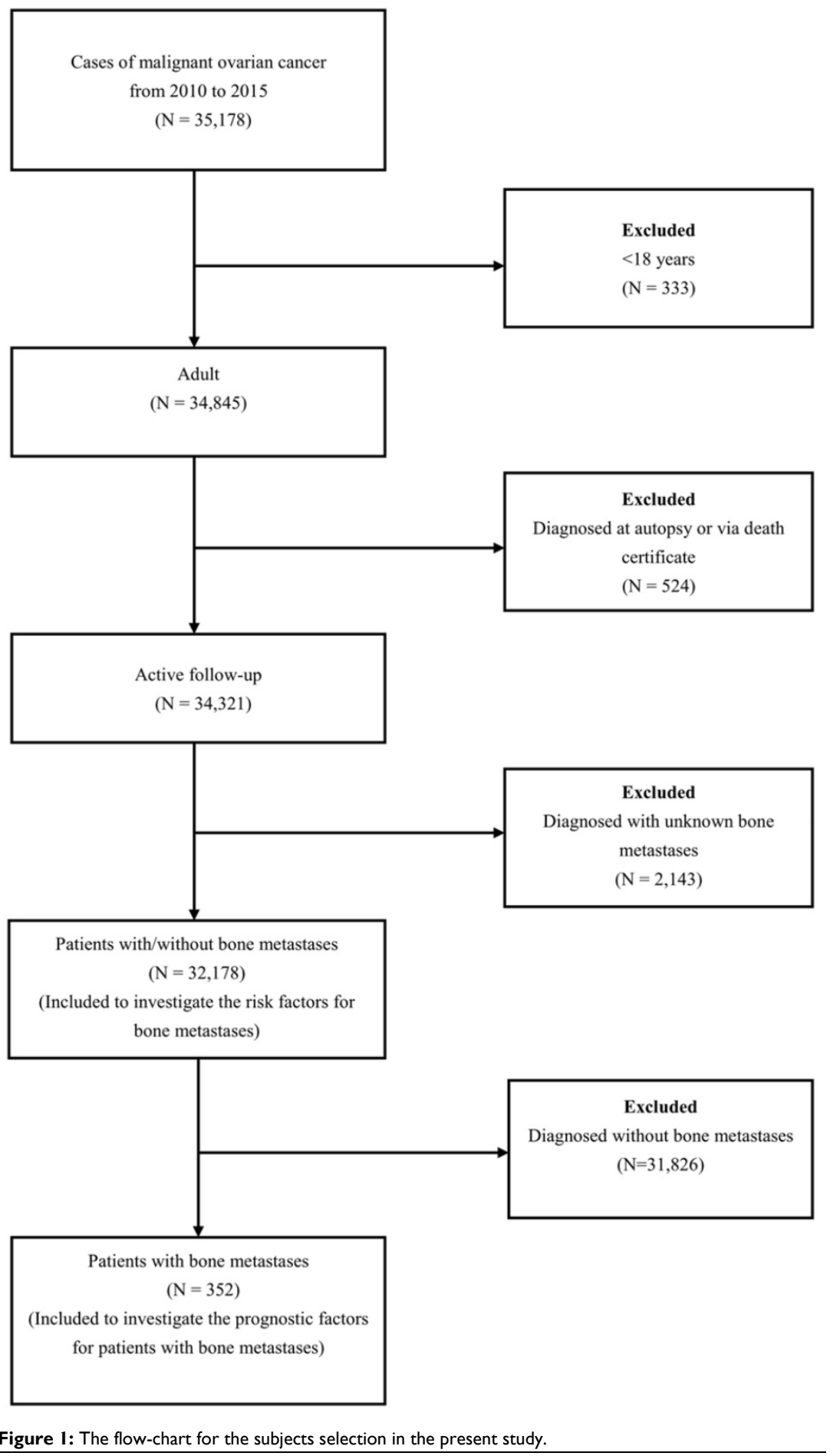

\section{Prevalence of BM}

352 OC patients were diagnosed with de novo BM $(1.09 \%)$. There is significant difference in the BM prevalence across different age groups $\left(\chi^{2}=16.29\right.$, $P<0.001)$, and the prevalence in the advanced ages groups ( $\geq 65$ years) was higher than that in 18-40 years $\left(X^{2}=4.92, \quad P=0.027\right)$ and $41-64$ years $\left(\chi^{2}=14.21\right.$, $P=0.0002)$. Results also showed the BM prevalence in black (compared with white patients; $\chi^{2}=8.88, P=0.01$ ), unmarried status $\left(\chi^{2}=7.97, P=0.01\right)$, T2 stage $\left(X^{2}=35.59, P<0.001\right), \quad N 1$ stage $\left(\chi^{2}=74.84, P<0.001\right)$, poor differentiated grade $\left(X^{2}=20.69, P<0.001\right)$, non-serous $\left(X^{2}=70.89, P<0.001\right)$, elevated CA-125 $\left(X^{2}=6.02, \quad P=0.01\right)$, lung metastases $\left(X^{2}=642.95, P<0.001\right)$, liver metastases $\left(X^{2}=606.90, \quad P<0.001\right) \quad$ and brain metastases $\left(X^{2}=460.19, P<0.001\right)$ were all significantly higher than in the other groups (Table 1).

\section{Associated factors for developing BM}

Univariable logistic analysis showed the factors of advanced age, unmarried status, higher $\mathrm{T}$ stage, N1 stage, poor differentiated grade, non-serous histology, elevated CA-125, the presence of lung metastases, liver metastases, and brain metastases were all positively associated with BM risk (Table 2).

Multivariable logistic regression indicated advanced age was negatively associated with $\mathrm{BM}$, while the T2/T1 stage, N1/N0 stage, non-serous and the presence of lung and liver metastases were positively associated with de novo BM development (Table 2).

\section{Survival analysis and prognostic factors for BM}

Once patients developed BM, OC patients' survival was dramatically decreased. The median survival of the cohort was 50.00 months (95\% CI: 48.44-51.56 months), while for the 352 OC patients with de novo BM, median survival was 5.00 months (95\% CI: 3.76-6.24 months, Figure 2 A). Kaplan-Meier analysis showed the overall survival in subjects with advanced age (Figure $2 \mathrm{~B}, P=0.01$ ), unmarried status (Figure $2 \mathrm{C}, P=0.004$ ), 
non-serous (Figure $2 \mathrm{D}, P<0.001$ ) and with lung metastases (Figure $2 \mathrm{E}, P=0.02$ ) and liver metastases (Figure $2 \mathrm{~F}, P=0.001$ ) were shorter than their counterparts. Patients with surgical treatment of the primary site presented significantly higher overall survival rate than those without surgery (Figure $2 \mathrm{G}$, $P<0.001)$.

Table 1. Demographic and clinical characteristics for ovarian cancer patients diagnosed with and without bone metastasis.

\begin{tabular}{|c|c|c|c|c|}
\hline \multirow{2}{*}{$\begin{array}{l}\text { Subject } \\
\text { characteristics }\end{array}$} & \multicolumn{2}{|c|}{ No. of ovarian cancer patients (2010-2015) } & \multirow[t]{2}{*}{$x^{2}$} & \multirow[t]{2}{*}{$P$-value } \\
\hline & $\begin{array}{l}\text { With BM (N=352, } \\
1.09 \%)\end{array}$ & $\begin{array}{l}\text { Without BM } \\
(\mathrm{N}=31826,98.91 \%)\end{array}$ & & \\
\hline Age, in years & & & 16.29 & $<0.001$ \\
\hline $18-40$ & $20(0.82)$ & 2413(99.18) & & \\
\hline $41-64$ & $151(0.91)$ & 16417(99.09) & & \\
\hline$\geq 65$ & 181(1.37) & 12996(98.63) & & \\
\hline Race & & & 8.88 & 0.01 \\
\hline White & 283(1.08) & 25963(98.92) & & \\
\hline Black & $45(1.60)$ & $2767(98.40)$ & & \\
\hline Others & $24(0.81)$ & 2939(99.19) & & \\
\hline Unknown & $0(0.00)$ & 157(100.00) & & \\
\hline Marital status & & & 7.97 & 0.01 \\
\hline Married & $145(0.94)$ & 15359(99.06) & & \\
\hline Unmarried & 193(1.27) & 14982(98.73) & & \\
\hline Unknown & $14(0.93)$ & 1485(99.07) & & \\
\hline Insurance & & & 0.36 & 0.55 \\
\hline Insured & $326(1.07)$ & $30140(98.93)$ & & \\
\hline Uninsured & $15(1.25)$ & $1182(98.75)$ & & \\
\hline Unknown & $11(2.14)$ & $504(97.86)$ & & \\
\hline Laterality & & & 5.01 & 0.08 \\
\hline Left & $52(0.63)$ & $8236(99.37)$ & & \\
\hline Right & $75(0.87)$ & $8579(99.13)$ & & \\
\hline Bilateral & $63(0.62)$ & 10093(99.38) & & \\
\hline Unknown & 162(3.19) & $4918(96.81)$ & & \\
\hline T stage & & & 35.59 & $<0.001$ \\
\hline $\mathrm{T} 1$ & $23(0.26)$ & $8727(99.74)$ & & \\
\hline $\mathrm{T} 2$ & $46(1.07)$ & $4253(98.93)$ & & \\
\hline $\mathrm{T} 3$ & $129(0.80)$ & 16097(99.20) & & \\
\hline Unknown & $154(5.30)$ & $2749(94.70)$ & & \\
\hline N stage & & & 74.84 & $<0.001$ \\
\hline No & 134(0.59) & $22550(99.41)$ & & \\
\hline $\mathrm{N} 1$ & 111(1.70) & $6426(98.30)$ & & \\
\hline Unknown & $107(3.62)$ & $2850(96.38)$ & & \\
\hline Grade & & & 20.69 & $<0.001$ \\
\hline I & $4(0.17)$ & $2336(99.83)$ & & \\
\hline II & $7(0.21)$ & $3331(99.79)$ & & \\
\hline III & $66(0.76)$ & $8618(99.24)$ & & \\
\hline IV & $34(0.54)$ & 6314(99.46) & & \\
\hline Unknown & $241(2.10)$ & $11227(97.90)$ & & \\
\hline Histology & & & 41.37 & $<0.001$ \\
\hline Serous & $87(0.58)$ & $14815(99.42)$ & & \\
\hline Non-serous & $205(1.30)$ & $15609(98.70)$ & & \\
\hline Unknown & $60(4.10)$ & 1402(95.90) & & \\
\hline CA-125 & & & 6.02 & 0.01 \\
\hline Normal & $15(0.52)$ & 2853(99.48) & & \\
\hline Elevated & $215(0.99)$ & 21441(99.01) & & \\
\hline Unknown & 122(1.59) & $7532(98.41)$ & & \\
\hline Lung Met & & & 642.95 & $<0.001$ \\
\hline None & 207(0.69) & 29879(99.31) & & \\
\hline Yes & $127(6.87)$ & $1722(93.13)$ & & \\
\hline Unknown & $18(7.41)$ & $225(92.59)$ & & \\
\hline Liver Met & & & 606.90 & $<0.001$ \\
\hline None & $200(0.67)$ & 29636(99.33) & & \\
\hline Yes & $136(6.24)$ & $2043(93.76)$ & & \\
\hline Unknown & 16(9.82) & $147(90.18)$ & & \\
\hline Brain Met & & & 460.19 & $<0.001$ \\
\hline None & $301(0.94)$ & $31705(99.06)$ & & \\
\hline Yes & $20(24.69)$ & $61(75.31)$ & & \\
\hline Unknown & $31(34.07)$ & $60(65.93)$ & & \\
\hline
\end{tabular}

\begin{tabular}{|c|c|c|c|c|}
\hline \multirow{2}{*}{$\begin{array}{l}\text { Subject } \\
\text { characteristics }\end{array}$} & \multicolumn{2}{|c|}{ No. of ovarian cancer patients (2010-2015) } & \multirow[t]{2}{*}{$x^{2}$} & \multirow[t]{2}{*}{$P$-value } \\
\hline & $\begin{array}{l}\text { With BM (N=352, } \\
1.09 \%)\end{array}$ & $\begin{array}{l}\text { Without BM } \\
\text { (N=31826, 98.91\%) }\end{array}$ & & \\
\hline Sur(pri) & & & 526.89 & $<0.001$ \\
\hline None & $250(3.63)$ & $6645(96.37)$ & & \\
\hline Yes & $99(0.39)$ & 25132(99.61) & & \\
\hline Unknown & $3(5.77)$ & $49(94.23)$ & & \\
\hline
\end{tabular}

Table 2. Univariable and Multivariable Logistic Regression for analyzing the associated factors for developing bone metastases in ovarian cancer patients.

\begin{tabular}{|c|c|c|c|c|}
\hline \multirow{2}{*}{$\begin{array}{l}\text { Subject } \\
\text { characteristics }\end{array}$} & \multicolumn{2}{|l|}{ Univariable } & \multicolumn{2}{|l|}{ Multivariable } \\
\hline & OR $(95 \% \mathrm{CI})$ & $P$-value & OR $(95 \% \mathrm{CI})$ & $P$-value \\
\hline \multicolumn{5}{|l|}{ Age, in years } \\
\hline $18-40$ & Reference & 1.00 & Reference & 1.00 \\
\hline $41-64$ & $1.11(0.70-1.77)$ & 0.66 & $0.40(0.16-1.01)$ & 0.05 \\
\hline$\geq 65$ & $1.68(1.06-2.67)$ & 0.03 & $0.35(0.13-0.95)$ & 0.04 \\
\hline \multicolumn{5}{|l|}{ Marital status } \\
\hline Married & Reference & 1.00 & Reference & 1.00 \\
\hline Unmarried & $1.37(1.10-1.69)$ & 0.01 & $0.92(0.51-1.65)$ & 0.77 \\
\hline Unknown & NA & NA & NA & NA \\
\hline \multicolumn{5}{|l|}{ T stage } \\
\hline $\mathrm{T} 1$ & Reference & 1.00 & Reference & 1.00 \\
\hline $\mathrm{T} 2$ & $4.10(2.49-6.78)$ & $<0.001$ & $3.39(1.11-10.33)$ & 0.03 \\
\hline $\mathrm{T} 3$ & $3.04(1.95-4.74)$ & $<0.001$ & $1.78(0.59-5.39)$ & 0.31 \\
\hline Unknown & NA & NA & $\mathrm{NA}$ & NA \\
\hline \multicolumn{5}{|l|}{ N stage } \\
\hline No & Reference & 1.00 & Reference & 1.00 \\
\hline N1 & $2.91(2.26-3.74)$ & $<0.001$ & $3.17(1.72-5.84)$ & $<0.001$ \\
\hline Unknown & NA & NA & NA & NA \\
\hline \multicolumn{5}{|l|}{$\begin{array}{l}\text { Differentiated } \\
\text { Grade }\end{array}$} \\
\hline I & Reference & 1.00 & Reference & 1.00 \\
\hline II & $1.23(0.36-4.20)$ & 0.74 & $2.04(0.22-18.71)$ & 0.53 \\
\hline III & $4.47(1.63-12.28)$ & 0.004 & $4.62(0.60-35.80)$ & 0.14 \\
\hline IV & $3.15(1.12-8.87)$ & 0.03 & $3.40(0.42-27.48)$ & 0.25 \\
\hline Unknown & NA & NA & NA & NA \\
\hline \multicolumn{5}{|l|}{ Histology } \\
\hline Serous & Reference & 1.00 & Reference & 1.00 \\
\hline Non-serous & $2.24(1.74-2.88)$ & $<0.001$ & $3.05(1.63-5.72)$ & 0.001 \\
\hline Unknown & NA & NA & NA & NA \\
\hline \multicolumn{5}{|l|}{ CA-125 } \\
\hline Normal & Reference & 1.00 & Reference & 1.00 \\
\hline Elevated & $1.91(1.13-3.22)$ & 0.02 & $1.33(0.49-3.58)$ & 0.58 \\
\hline Unknown & NA & NA & NA & NA \\
\hline \multicolumn{5}{|l|}{ Lung Met } \\
\hline None & Reference & 1.00 & Reference & 1.00 \\
\hline Yes & $10.65(8.49-13.35)$ & $<0.001$ & $8.57(4.37-16.80)$ & $<0.001$ \\
\hline Unknown & NA & NA & NA & NA \\
\hline \multicolumn{5}{|l|}{ Liver Met } \\
\hline None & Reference & 1.00 & Reference & 1.00 \\
\hline Yes & $9.86(7.90-12.32)$ & $<0.001$ & $4.95(2.50-9.82)$ & $<0.001$ \\
\hline Unknown & NA & NA & NA & NA \\
\hline \multicolumn{5}{|l|}{ Brain Met } \\
\hline None & Reference & 1.00 & Reference & 1.00 \\
\hline Yes & $34.54(20.58-57.95)$ & $<0.001$ & $5.37(0.37-77.85)$ & 0.22 \\
\hline Unknown & NA & NA & NA & NA \\
\hline
\end{tabular}

Multivariable Cox regression results incorporating the aforementioned significant factors showed that non-serous histology [Hazard ratio $(\mathrm{HR})=3.05 ; 95 \% \mathrm{CI}: 1.63-5.72 ; P=0.001]$ was positively associated with overall death, while the surgery of the primary site (HR=0.42; 95\% CI: 0.29-0.61; $P<0.001$ ) were showed to be negatively associated with overall death risk. Moreover, the median survival time could 
be prolonged from 3.00 (95\% CI: 2.20-3.80) months to 18.00 (95\% CI: 10.82-25.18) months in patients with history of primary site surgery (Table 3 ).

Table 3. Multivariable Cox Regression for analyzing the prognosis factors for ovarian cancer with bone metastases.

\begin{tabular}{llll}
\hline Subject characteristics & Survival, Median (IQR), month & HR $(95 \% \mathrm{CI})$ & $P$-value \\
\hline Age, years & & & \\
$18-40$ & $4.00(2.91-5.09)$ & Reference & 1.00 \\
$41-64$ & $7.00(5.14-8.85)$ & $0.73(0.42-1.26)$ & 0.26 \\
$\geq 65$ & $3.00(2.05-3.95)$ & $0.73(0.42-1.25)$ & 0.25 \\
Marital status & & & \\
Married & $7.00(4.73-9.27)$ & Reference & 1.00 \\
Unmarried & $3.00(2.03-3.97)$ & $1.11(0.82-1.49)$ & 0.49 \\
Unknown & NA & NA & NA \\
Histology & & & \\
Serous & $18.00(9.13-26.87)$ & Reference & 1.00 \\
Non-serous & $3.00(1.93-4.08)$ & $1.44(1.01-2.06)$ & 0.046 \\
Unknown & NA & NA & NA \\
Lung Met & & & \\
None & $6.00(4.04-7.96)$ & Reference & 1.00 \\
Yes & $3.00(1.48-4.52)$ & $1.15(0.84-1.58)$ & 0.37 \\
Unknown & NA & NA & NA \\
Liver Met & & & \\
None & $6.00(4.28-7.72)$ & Reference & 1.00 \\
Yes & $3.00(1.52-4.49)$ & $1.20(0.88-1.64)$ & 0.25 \\
Unknown & NA & NA & NA \\
Sur(pri) & & & \\
\hline
\end{tabular}

\begin{tabular}{llll}
\hline Subject characteristics & Survival, Median (IQR), month & HR $(95 \% \mathrm{CI})$ & $P$-value \\
\hline None & $3.00(2.20-3.80)$ & Reference & 1.00 \\
Yes & $18.00(10.82-25.18)$ & $0.42(0.29-0.61)$ & $<0.001$ \\
Unknown & NA & NA & NA \\
\hline
\end{tabular}

Abbreviations: Met=metastases; Sur(pri)=surgical treatments of primary site,

NA=Not available, all factors with Unknown data were removed from Cox and

Kaplan-Meier model.

\section{Discussion}

One of the greatest strengths of the present study was the large sample size provided by SEER database. With the large population, the present study was the first time looking into both risk factors for BM occurrence and prognostic factors of OC patients with BM. Based on our cohort analyses, $1.09 \%$ of the OC patients were diagnosed with de novo BM, which was consistent with previous studies. It was previously reported that the incidence of BM ranged from $1.5 \%$ to $3.74 \%$ among OC patients $[1,11]$. However, the prevalence of BM in OC was 15\% in autopsy studies, because approximately $50 \%$ of the metastatic sites were asymptomatic [12].
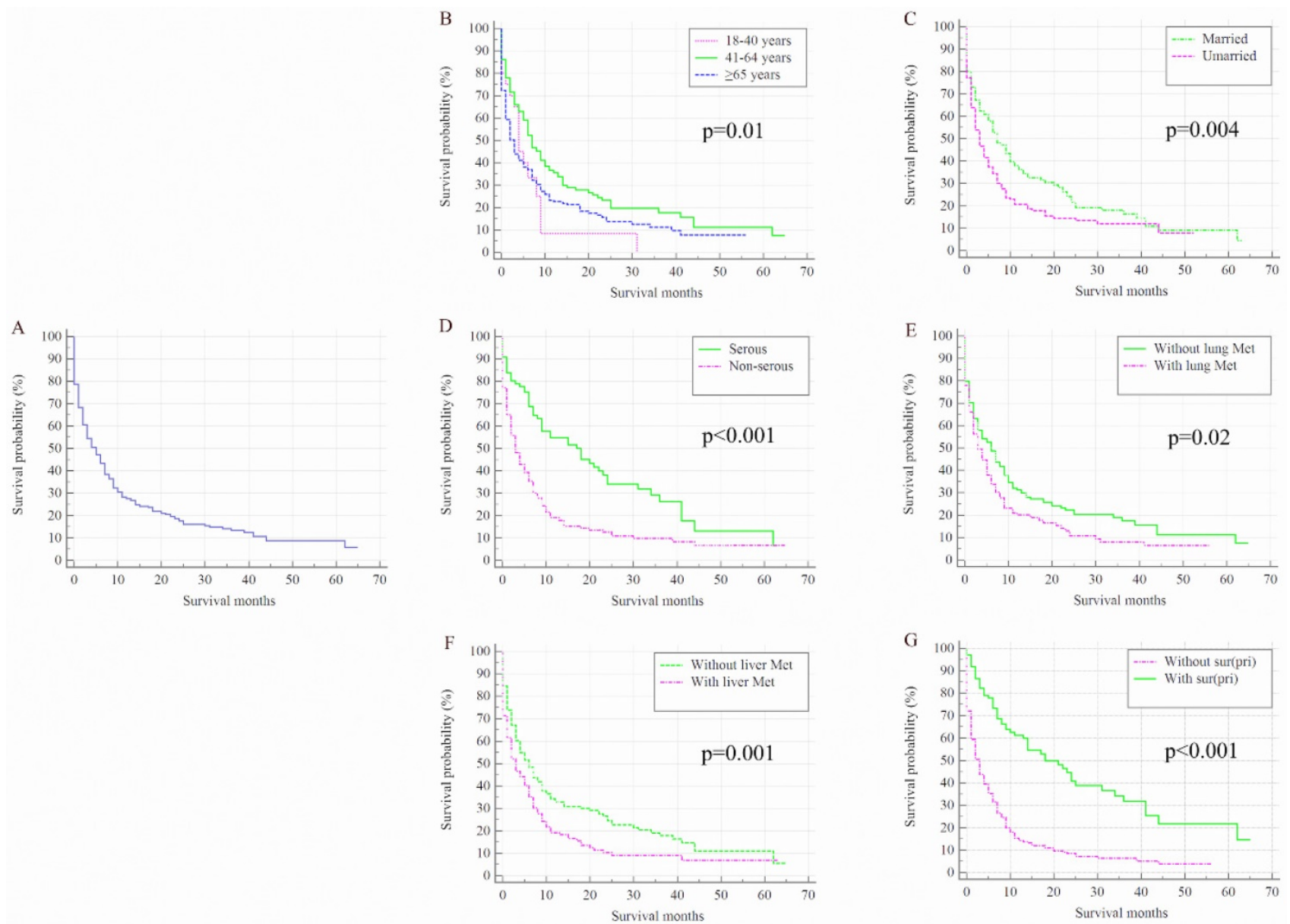

Figure 2: Kaplan-Meier analysis of overall survival among ovarian cancer patients who were diagnosed with bone metastases for total population (A) and stratified by age (B), marital status (C), histology (D), and the presence of lung metastases (E), liver metastases (F), and surgical treatment $(G)$. OC=ovarian cancer; Lung Met=lung metastases; Liver Met=liver metastases. 
According to our extensive literature review, this is the first time to investigate the associated factors for BM in OC patients. A previous study suggested advanced stage, poor differentiated grade, and lymph node involvement were positively associated with development of distant metastases [7]. The present study added to the literature by showing older age, T2/T1 stage, N1/N0 stage, non-serous and the presence of lung and liver metastases were all significantly associated with de novo BM development. Risk factors identification is important for guiding clinical treatment procedures. The prophylactic treatment and nursing can be given to the OC patients with more risk factors. Screening examinations such as skeletal radiographic scanning and/or PET-CT can be recommended for the patients with high BM risk. A predictive system can be fabricated to quantitively evaluate the probability of the BM development in the future.

The association between histological types and $\mathrm{BM}$ development in OC is still controversial. A series of studies reported that the histological types did not affect the development of BM [13-15]. Based on previous autopsy studies with the limited sample size, Abdul-Karim and colleagues reported that BM tends to occur in high-grade carcinomas instead of low-grade cases, and was observed in three cases with papillary serous adenocarcinomas, two mixed adenosquamous carcinomas and one clear cell carcinoma [16]. Julian et al. reported three OC patients with BM, two of them were papillary serous carcinoma and one was with mucinous carcinoma [17]. In the present study with a large sample, we proved that BM has a significant higher probability developed in non-serous OC.

Previous studies showed BM could significantly worsen the prognosis of cancer patients [18-21]. The median survival of OC patients with BM were reported to be approximately 8 months [7, 22, 23]. In the present study, the median survival of the entire cohort was 50.00 months, while that of OC patients with de novo BM decreased to 5.00 months. A surprising finding of the present study was the fact that the median survival time can be prolonged from 3.00 months to 18.00 months with primary tumour surgery. Thus, aggressive surgery is encouraged for OC patients with BM. At the same time, non-serous histology showed the negative association with the overall survival. Physicians should pay high attention to the OC patients with the non-serous histological type.

The present study showed the number of BM patients with lung, liver or brain metastasis was lower than those without. BM patients with the present of lung, liver or brain metastasis worsen the prognosis.
It is acknowledged that this study has several limitations. First, the observed BM incidence has to be interpreted as a strong underestimate of the real figure, this is due to the patients who developed BM later in their disease course were not recorded by SEER dataset. Second, the SEER dataset lacks patient comorbidity profiles such as disease history, skeletal related events (SREs) and the patients' preference to receive surgery, which may partly affect the precision of the results for the prognostic analyses. We found correlation between primary tumor surgery and improved survival among ovarian cancer patients with bone metastases. Due to the insufficient information recorded by SEER on history of diseases and treatment morbidity, external validation is warranted in future. Third, it was not recommended to perform the survival analysis on the SEER cohort as the records of radiotherapy and chemotherapy were lacking [24]. Thus, therapeutic related prognostic analyses were not conducted. Last but not least, the diagnostic modes for ovarian cancer patients with bone metastases cannot be analyzed for data undocumented in the SEER database.

\section{Conclusions}

The cohort in our study represents the largest dataset of $\mathrm{BM}$ in $\mathrm{OC}$ to date and offers valuable information on the epidemiological characteristics and prognosis for $\mathrm{BM}$ in the OC patient population. The present study provides a uniquely detailed description of associated factors for BM to improve our understanding of BM in OC and potentially guide its clinical procedures.

Bone manifestation is rare in OC patients. A list of risk factors for de novo BM development in OC were identified, including older age, T2/T1 stage, $\mathrm{N} 1 / \mathrm{N} 0$ stage, non-serous and the presence of lung and liver metastases. The prognosis of OC patients with de novo BM is poor, with the median survival being 5.00 months. Non-serous histology was positively associated with overall death. Primary tumor surgery was negatively associated with the overall death risk in the present study, more studies with detailed treatment information are needed to further confirm the results.

\section{Acknowledgments}

We thank Patricia Douglas for editing the language of the manuscript. We thank Yile Lin, Dengming Yan, Xuehang Ge, Jincai Duan, and Chong Zhang for their contribution on collecting data.

\section{Ethics approval and consent to participate}

Cancer is a reportable disease in every state of the United States. The data in the SEER database does 
not require informed patient consent. The present study was complied with the 1964 Helsinki Declaration and its later amendments or comparable ethical standards. This study used previously collected deidentified data, which was deemed exempt from review by the Ethics Board of the Tianjin Medical University Cancer Institute and Hospital.

\section{Availability of data and material}

The datasets generated and/or analysed during the current study are available in the SEER repository, https://seer.cancer.gov/data/.

\section{Funding}

The present study was sponsored by Natural Science Foundation of China (81702161, 81802508, 81801781, 81872184), the grant of Russian Foundation of Basic Research (15-29-01338), Natural Science Foundation of Tianjin Science and Technology Committee China (17JCQNJC11000), Natural Science Foundation of Tianjin Medical University (2016KYZQ10), The Doctor Start-up Grant of Tianjin Medical University Cancer Institute and Hospital (B1612, B1711) and Top talent training program of the first affiliated hospital of PLA Army Medical University [SWH2018BJKJ-12].

\section{Author contributions}

$\mathrm{CZ}, \mathrm{XG}$ and $\mathrm{XW}$ designed the study. WM, LQ and $Y Z$ collected the data. $X W, X G$ and $X H$ analyzed the data. $C Z, K P, X G$, and $X W$ organized the manuscript. VB, LQ, VC, KP, YY, YM and GW reviewed the papers and revised the manuscript. All the authors $(\mathrm{CZ}, \mathrm{XG}, \mathrm{KP}, \mathrm{WM}, \mathrm{LQ}, \mathrm{YZ}, \mathrm{XH}, \mathrm{VB}, \mathrm{YY}$, $\mathrm{GW}, \mathrm{VC}, \mathrm{XW}$ and $\mathrm{YM}$ ) have read and approved the final manuscript. All authors contributed toward data analysis, drafting and revising the paper and agree to be accountable for all aspects of the work.

\section{Competing Interests}

The authors have declared that no competing interest exists.

\section{References}

1. Jelovac D, Armstrong DK. Recent progress in the diagnosis and treatment of ovarian cancer. CA Cancer J Clin. 2011;61(3):183-203.

2. Cancer.net.

https://www.cancer.net/cancer-types/ovarian-fallopian-tube-and-peritoneal -cancer/statistics. Accessed 11th Aug 2018

3. Yeung TL, Leung CS, Yip KP, Au Yeung CL, Wong ST, Mok SC. Cellular and molecular processes in ovarian cancer metastasis. A Review in the Theme: Cell and Molecular Processes in Cancer Metastasis. Am J Physiol Cell Physiol. 2015;309(7):C444-56

4. Jemal A, Siegel R, Xu J, Ward E. Cancer statistics, 2010. CA Cancer J Clin. 2010;60(5):277-300.

5. Nasioudis D, Ko EM, Haggerty AF, Giuntoli RL 2nd, Burger RA, Morgan MA, Latif NA. Isolated distant lymph node metastases in ovarian cancer. Should a new substage be created? Gynecol Oncol Rep. 2019; 28:86-90.

6. Jelovac D, Armstrong DK. Recent progress in the diagnosis and treatment of ovarian cancer. CA Cancer J Clin. 2011;61(3):183-203.
7. Deng K, Yang C, Tan Q, Song W, Lu M, Zhao W, Lou G, Li Z, Li K, Hou Y. Sites of distant metastases and overall survival in ovarian cancer: A study of 1481 patients. Gynecol Oncol. 2018. 150(3):460-465.

8. Hage WD, Aboulafia AJ, Aboulafia DM. Incidence, location, and diagnostic evaluation of metastatic bone disease. Orthop Clin North Am. 2000;31(4):515-528.

9. Thanapprapasr D, Nartthanarung A, Likittanasombut P, Na Ayudhya NI, Charakorn C, Udomsubpayakul U, Subhadarbandhu T, Wilailak S. Bone metastasis in cervical cancer patients over a 10-year period. Int J Gynecol Cancer. 2010;20(3):373-378

10. Áyen Á, Jiménez Martínez Y, Marchal JA, Boulaiz H. Recent Progress in Gene Therapy for Ovarian Cancer. Int J Mol Sci. 2018;19(7).

11. Sehouli J, Olschewski J, Schotters V, Fotopoulou C, Pietzner K. Prognostic role of early versus late onset of bone metastasis in patients with carcinoma of the ovary, peritoneum and fallopian tube. Ann Oncol. 2013;24(12):3024-8.

12. Dauplat J, Hacker NF, Nieberg RK, Berek JS, Rose TP, Sagae S. Distant metastases in epithelial ovarian carcinoma. Cancer. 1987;60(7):1561-6.

13. Rose PG, Piver MS, Tsukada Y, Lau TS. Metastatic patterns in histologic variants of ovarian cancer. An autopsy study. Cancer. 1989;64(7):1508-13.

14. Bergman F. Carcinoma of the ovary. A clinicopathological study of 86 autopsied cases with special reference to mode of spread. Acta Obstet Gynecol Scand. 1966;45(2):211-31.

15. Dvoretsky PM, Richards KA, Angel C, Rabinowitz L, Stoler MH, Beecham JB, Bonfiglio TA. Distribution of disease at autopsy in 100 women with ovarian cancer. Hum Pathol. 1988;19(1):57-63.

16. Abdul-Karim FW, Kida M, Wentz WB, Carter JR, Sorensen K, Macfee M, Zika J, Makley JT. Bone metastasis from gynecologic carcinomas: a clinicopathologic study. Gynecol Oncol. 1990;39(2):108-114.

17. Julian CG, Goss J, Blanchard K, Woodruff JD. Biologic behavior of primary ovarian malignancy. Obstet Gynecol. 1974;44(6):873-84.

18. Baize N, Mahamat A, Benizri E, Saint-Paul MC, Mounier N. Bone metastasis from endometrioid ovarian carcinoma: a case study and literature review. Eur J Gynaecol Oncol. 2009;30(3):326-8.

19. Zhang Y, Guo X, Wang G, Ma W, Liu R, Han X, Li L, Baklaushev VP, Bryukhovetskiy AS, Wang W, Wang X, Zhang C. Real-World Study of the Incidence, Risk Factors, and Prognostic Factors Associated with Bone Metastases in Women with Uterine Cervical Cancer Using Surveillance, Epidemiology, and End Results (SEER) Data Analysis. Med Sci Monit. 2018; 24:6387-6397.

20. Zhang C, Mao M, Guo X, Cui P, Zhang L, Xu Y, Li L, Han X, Peltzer K, Xiong S, Baklaushev VP, Wang $X$, Wang G. Nomogram based on homogeneous and heterogeneous associated factors for predicting bone metastases in patients with different histological types of lung cancer. BMC Cancer. 2019; 19(1):238.

21. Guo X, Zhang C, Ma W, Tian F, Xu G, Han X, Sun P, Baklaushev VP, Bryukhovetskiy AS, Wang G, Ma Y, Wang X. Patterns of bone metastases in newly diagnosed colorectal cancer: a real-world analysis in the SEER database. Int J Colorectal Dis. 2019; 34(3):533-543.

22. Chen $\mathrm{YL}, \mathrm{Hsiao} \mathrm{SM}$, Lin MC, Lin $\mathrm{HH}$. Bone metastasis as the initial presentation in one case of ovarian cancer with two components of endometrioid adenocarcinoma and adenosarcoma. Taiwan J Obstet Gynecol. 2009;48(3):298-301.

23. Cheng B, Lu W, Xiaoyun W, YaXia C, Xie X. Extra-abdominal metastases from epithelial ovarian carcinoma: an analysis of 20 cases. Int J Gynecol Cancer. 2009;19(4):611-4.

24. Noone AM, Lund JL, Mariotto A, Cronin K, McNeel T, Deapen D, Warren JL. Comparison of SEER Treatment Data With Medicare Claims. Med Care. 2016;54(9):e55-64. 